\title{
IMPLEMENTASI CUSTOMER RELATIONSHIP MANAGEMENT DI USAHA MIKRO KECIL DAN MENENGAH BIDANG OTOMOTIF
}

\author{
Nicholas Arizona Manurung ${ }^{1}$, Agung Nugroho ${ }^{2}$ \\ ${ }^{1,2}$ Fakultas Ekonomi dan Bisnis Universitas Indonesia \\ Email: a.nugroho@ui.ac.id
}

\begin{abstract}
This research discuss the Implementaion of Customer Relationship Management (CRM) strategy in Small and Medium Entreprise 'Trijaya Ban 83' workshop that focusing on service repairment industry. The mapping of business condition mention that there is no service differentiation with big and small customer. There are some gap situation in Trijaya Ban 83 workshop such as there is no intense service treatment for customers who generate biggest profit and there is no comprehensive customer database. In this business coaching, coach want to help the business to create a comprehensive Customer Relationship Management Strategy in purpose to increase customer loyalty and keep contributing profit to Trijaya Ban 83 workshop. Methods used in this thesis is qualitative method to gather and analyze customer data of Trijaya Ban 83 workshop in 2016. The result of this research is to create a customer categorization that needs service differently also the implementation to the focus category. The purpose of this Customer Relationship Management implementation is for the workshop to have a systematic selling dan the customer become more loyal in the thight competition of service repairment industry.
\end{abstract}

Keywords: Customer Relationship Management, Automotive Industry, Customer Loyalty, Business Coaching, Small and Medium Entreprises

\begin{abstract}
Abstrak. Penelitian ini membahas mengenai implementasi strategi Customer Relationship Management (CRM) pada Usaha Mikro Kecil dan Menengah / UMKM yang bergerak di bidang jasa bengkel yaitu Trijaya Ban 83. Pemetaan kondisi UKM memperlihatkan bahwa tidak ada perbedaan perlakuan service antara pelanggan besar dan kecil. Beberapa kesenjangan yang terdapat di bengkel Trijaya Ban 83 adalah belum adanya pelayanan lebih terhadap pelanggan yang memberi kontrbusi pendapatan terbesar dan belum ada database konsumen yang lengkap. Oleh karena itu, tujuan dari business coaching ini untuk membantu UKM merumuskan sebuah sistem Customer Relationship Management dengan harapan pelanggan akan semakin loyal dan terus memberikan laba untuk bengkel Trijaya Ban 83. Metode yang digunakan dalam penelitian ini adalah metode kualitatif untuk mengumpulkan dan menganalisis data pelanggan bengkel Trijaya Ban 83 selama tahun 2016. Kesimpulan dari penelitian ini adalah pengelompokan pelanggan fokus yang harus dilayani secara berbeda serta implementasi service yang diberikan kepada kelompok fokus tersebut. Harapan dari implementasi Customer Relationship Management adalah agar bengkel memiliki sistematis penjualan yang teratur dan pelanggan semakin loyal terhadap bengkel dikala kompetisi bengkel semakin ketat.
\end{abstract}

Kata kunci: Customer Relationship Management, Industri Otomotif, Loyalitas Pelanggan, Business

Coaching, Usaha Kecil dan Menengah

\section{PENDAHULUAN}

Usaha Mikro, Kecil dan Menengah (UMKM) merupakan industri yang menjadi pusat perhatian dalam pertumbuhan ekonomi Indonesia. Untuk mendukung hal tersebut, Bank Indonesia mengeluarkan peraturan Bank Indonesia (PBI) no. 14/22/PBI/2012 tanggal 21 desember 2012 mengenai pemberian kredit oleh bank umum dan bantuan teknis dalam rangka peningkatan bisnis usaha mikro, kecil dan menengah. PBI tersebut menjelaskan bahwa bank pada tahun 2015 harus memberikan porsi kredit minimal 5\% kepada UMKM dari total kredit yang dilontarkan. Bahkan pada tahun 2018 rasio kredit pembiayaan terhadap UMKM ditetapkan paling rendah sebesar $20 \%$ dari total kredit, dari sisi kualitas kredit yang dilontarkan, para bank juga harus memahami profil bisnis UMKM secara lebih mendalam sehingga 
penyaluran kredit tepat sasaran dan menghasilkan kredit berkualitas baik dan lancar.

Salah satu industri yang berperan besar dalam perkembangan ekonomi adalah industri otomotif, industri otomotif adalah industri yang merancang, mengembangkan, memproduksi, memasarkan dan menjual serta melakukan purna jual kendaraan bermotor. (kemendag.go.id). I Gusti Putu Suryawirawan, selaku Dirjen industri logam, mesin, alat transportasi dan elektronika, mengatakan bahwa peran sektor industri dalam kontribusi PDB adalah sebesar 18\% dimana 5\% merupakan sumbangsih dari industri otomotif (kemenperin.go.id, 2016).

Salah satu UMKM yang memberikan kontribusi pada industri otomotif adalah bengkel Trijaya Ban 83 yang berdiri pada tahun 1976 . Bengkel Trijaya Ban 83 saat ini merupakan usaha keluarga yang dikelola oleh keluarga Ibu Sri Muwarni selaku pemilik dan pengelola keuangan. Terdapat 4 manajer dibawah Ibu Sri Muwarni, yaitu Ibu Annisa, anak pertama Ibu Sri, yang menjadi manajer pembelian yang bertugas membeli persediaan barang serta peralatan Trijaya Ban 83, suami Ibu Annisa, yaitu Bapak Oldi, bertugas sebagai manajer penjualan yang bertujuan mencari bisnis skala perusahaan (business to business), anak kedua Ibu Sri, yaitu Ibu Nafisah bertugas sebagai manajer sumber daya danusia dan suami Ibu Nafisah, Bapak Ihsan bertugas sebagai manajer operasional. Untuk kegiatan operasional di Trijaya Ban 83, terdapat 5 divisi: Divisi Sales Counter, Divisi Mesin, Divisi Spooring, Divisi Gudang dan Divisi Bongkar Pasang.

Saat ini bengkel Trijaya Ban 83 memiliki tujuan untuk meningkatkan penjualan dikala daya saing bengkel di daerah Otto Iskandardinata yang cenderung sangat banyak. Upaya bengkel Trijaya Ban 83 untuk meningkatkan penjualannya bisa dicapai dengan memaksimalkan data pelanggan tetap yang sudah ada mengingat bengkel Trijaya Ban 83 sudah berdiri sangat lama, yaitu dengan melakukan cross selling dan follow up terhadap pelanggan tetap sehingga pelanggan tetap terjaga dan penjualan atas spare part dan service terus meningkat. Hal lain yang dapat dipetik dari tujuan bisnis ini adalah akan meningkatnya kepuasan pelanggan karena adanya follow up dari bengkel Trijaya Ban 83 .

\section{Pemetaan Kondisi UMKM}

\section{Analisis Internal}

Analisis internal digunakan perusahaan dalam mengidentifikasikan sumber daya yang bernilai dan bermanfaat yang dimiliki untuk menciptakan keunggulan daya saing dan keberlangungan bisnis ke depan. Menurut Barney (1991), Ada satu metode yang dapat digunakan untuk menganalisis kondisi internal perusahaan yaitu pendekatan VRIO. Analisa VRIO (Valuable, Rarity, Imitability and Organization) adalah alat untuk menganalisa sumber daya internal dan kapabilitas perusahaan mengenai daya saing perusahaan dalam berkompetisi dalam industri (Barney, 1991). Analisa VRIO mengajukan pertanyaan mengenai hal sebagai berikut:

\section{Valuable}

Mengetahui apakah sumber daya yang dimiliki oleh perusahaan dapat memberikan nilai tambah lebih yang dapat membuat perusahaan menang dalam kompetisi di industri sejenis. Jika memberikan nilai tambah maka sumber daya dapat dikatakan berharga, sumber daya juga dapat dikatakan berharga jika dapat menambah nilai suatu produk dan jasa.

2. Rarity

Sumber daya dapat dikatakan langka (rare) jika hanya dapat dimiliki oleh satu atau sedikit perusahan sejenis serta penting untuk mengetahui apakah competitor memiliki kontrol terhadap sumber daya yang langka. Sumber daya yang langka adalah sumber daya yang sulit diperoleh olah pesaing sejenis.

\section{Imitability}

Mengetahui seberapa mahal untuk suatu sumber daya agar dapat ditiru oleh perusahaan lain. Imitasi dapat memakai 2 cara, yaitu: duplikasi, dengan cara meniru $100 \%$ produk atau jasa yang ditawarkan dan substitusi, menawarkan produk/jasa yang memiliki fungsi sejenis.

\section{Organization}


Hal yang paling penting bagi perusahaan setelah memiliki sumber daya adalah memanfaatkan sumber daya tersebut semaksimal mungkin hingga memberikan benefit kepada perusahaan. Perusahaan memiliki komponen terakhir, organization, jika perusahaan dapat memanfaatkan sumber daya yang memiliki ketiga komponen diatas.

Berikut adalah analisa VRIO untuk bisnis bengkel UKM Trijaya Ban 83 yang didapat dari hasil interview:

Tabel 1. Analisa VRIO Trijaya Ban 83

\begin{tabular}{|c|c|c|c|c|c|}
\hline $\begin{array}{l}\text { Resource/ } \\
\text { capability }\end{array}$ & Valuable & Rare & Inimitable & Organization & $\begin{array}{l}\text { Competitive } \\
\text { Implication }\end{array}$ \\
\hline \multicolumn{6}{|l|}{ Tangible } \\
\hline Bangunan yang luas & Yes & No & No & No & Competitive Parity \\
\hline $\begin{array}{l}\text { Mesin Spooring \& } \\
\text { Lifter mobil }\end{array}$ & Yes & No & No & No & Competitive Parity \\
\hline $\begin{array}{ll}\begin{array}{l}\text { Lokasi } \\
\text { strategis }\end{array} & \text { yang } \\
\end{array}$ & Yes & No & No & No & Competitive Parity \\
\hline $\begin{array}{l}\text { Kemampuan } \\
\text { finansial }\end{array}$ & Yes & No & No & No & Competitive Parity \\
\hline $\begin{array}{l}\text { Perlengkapan yang } \\
\text { lengkap }\end{array}$ & Yes & No & No & No & Competitive Parity \\
\hline \multicolumn{6}{|l|}{ Intangibles } \\
\hline $\begin{array}{l}\text { Brand } \\
\text { Trijaya }\end{array}$ & Yes & Yes & Yes & Yes & $\begin{array}{l}\text { Sustained } \\
\text { Competitive } \\
\text { Advantage }\end{array}$ \\
\hline $\begin{array}{l}\text { Aliansi dengan } \\
\text { Bridgetone }\end{array}$ & Yes & Yes & No & No & $\begin{array}{l}\text { Temporary } \\
\text { Competitive } \\
\text { Advantage }\end{array}$ \\
\hline $\begin{array}{l}\text { Menjadi anggota } \\
\text { YDBA }\end{array}$ & Yes & Yes & Yes & Yes & $\begin{array}{l}\text { Sustained } \\
\text { Competitive } \\
\text { Advantage }\end{array}$ \\
\hline $\begin{array}{l}\text { Manajemen yang } \\
\text { handal }\end{array}$ & Yes & Yes & Yes & Yes & $\begin{array}{l}\text { Sustained } \\
\text { Competitive } \\
\text { Advantage }\end{array}$ \\
\hline Perizinan yang sah & Yes & No & No & No & Competitive Parity \\
\hline
\end{tabular}

Berdasarkan hasil analisa VRIO diatas, dapat dilihat bahwa Trijaya Ban tidak memiliki keunggulan dalam tangible asset jika dibandingkan denga pesaingnya karena barang dan jasa yang diperjualbelikan cenderung sama namun Trijaya Ban 83 memiliki keunggulan jangka panjang dalam intangible asset, yaitu: brand image Trijaya, Aliansi dengan Bridgestone, keanggotaan Yayasan Dharma Bakti Astra / YBDA dan manajemen yang handal. Kesimpulan yang diperoleh dari analisa VRIO adalah bengkel Trijaya Ban 83 perlu meningkatkan dan mempertahankan hal yang sudah menjadi kekuatan jangka panjang sebagai nilai tambah untuk memenangkan kompetisi di dunia perbengkelan. Untuk aset yang memberikan keunggulan jangka pendek seperti lokasi yang strategis dan bangunan yang luas, hal ini perlu ditingkatkan dan dikelola agar dapat menjadi keunggulan jangka panjang.

\section{Analisis Eksternal}

Analisis eksternal dari Trijaya Ban 83 bisa didapatkan dengan menggunakan 2 analisis, yaitu analisis model lima kekuatan dari Michael Porter dan analisis PESTEL (Politic, Economy, Social, Technology). Analisis pertama, yaitu analisis model lima kekuatan Porter yang dicetuskan oleh Michael Porter merupakan metode yang populer digunakan dalam menganalisis keadaan eksternal dari suatu perusahaan. Menurut David (2011), metode ini menjadi landasan perumusan kebijakan strategis bagi perusahaan di lintas industri karena sifatnya yang mampu 
menggambarkan secara komperhensif ancaman eksternal yang siap menerjang perusahaan. Michael Porter berpendapat bahwa ada lima kekuatan yang terbentuk secara alami dalam suatu persaingan usaha (Gamble et al, 2015:42). Kelima kekuatan ini menjadi penamaan teori yang dihasilkan oleh Porter. Kelima aspek kekuataan tersebut, yaitu rivalitas diantara perusahan yang bersaing, potensi masuknya pesaing baru, ancaman dari produk substitusi, daya tawar pemasok, dan daya tawar konsumen.

Berdasarkan analisis model lima kekuatan Porter di bengkel Trijaya maka terlihat persaingan bisnis di industri bengkel, terutama di sekitar bengkel Trijaya Ban 83, berada pada tingkat persaingan yang medium ke tinggi. Hal ini karena banyaknya kompetitor yang membuka bengkel di jalan Otista Raya. Alasan yang mendorong banyaknya kompetitor di jalan Otista Raya karena wilayah Otista terkenal sebagai salah satu pusat suku cadang kendaraan bermotor di Jakarta. Potensi masuknya kompetitor baru di industri bengkel terlihat cukup rendah. Hal ini didorong oleh beberapa faktor, yaitu pertama, bengkel lama yang sudah beroperasi puluhan tahun telah mendominasi pasar sehingga jarang adanya bengkel baru di Otista Raya. Kedua, pemain baru membutuhkan modal finansial yang besar untuk mendirikan bengkel baru. Ketiga, proses perijinan yang panjang dan waktu yang lama untuk menciptakan reputasi baik bagi bengkel membuat banyak pemain baru berpikir dua kali dalam memasuki industri bengkel Barang-barang substitusi dari produk yang ditawarkan oleh Trijaya Ban 83 mulai muncul dengan berkembangnya teknologi informasi. Contoh dari kemajuan IT yang menimbulkan tantangan baru bagi Trijaya Ban 83 adalah substitusi produk yang ditawarkan oleh tyrepac.co.id. Tidak adanya perantara diantara produsen dan konsumen membuat mayoritas barang yang dijual melalui internet akan lebih murah. Hal serupa terjadi dengan ban yang dijual oleh tyrepac.co.id menjadi jauh lebih murah daripada harga ban yang ditawarkan oleh Trijaya Ban 83 dan distributor resmi. Pada aspek daya tawar pemasok, Trijaya memiliki posisi yang cukup kuat karena memiliki 4 distributor untuk membeli ban. Pada aspek posisi daya tawar yang dimiliki konsumen terhadap Trijaya Ban 83 sangat kuat. Ketergantungan yang signifikan dari konsumen terlihat dari proporsi pendapatan Trijaya Ban 83 yang masih di dominasi dari penjualan kepada konsumen end-user (B2C) sebesar 54 persen. Potensi konsumen korporasi sangat besar apabila Trijaya Ban 83 mulai mengarahkan strategi kepada segmen konsumen tersebut.

Berdasarkan indikator-indikator yang dihasilkan dengan analisis model lima kekuatan Poter disertai penilaian dan argumentasi alasan terhadap masing-masing indikator, maka disimpulkan bahwa industri yang sedang dijalani oleh Trijaya Ban 83 termasuk industri yang kurang menarik karena dua alasan. Pertama, Bengkel sudah terlalu banyak dan hampir menjadi suatu usaha yang bersifat komoditas membuat tingkat persaingan diantara para bengkel tergolong medium-high. Adanya ancaman dari e-commerce yang baru, yaitu Tyrepac yang dapat memberikan harga ban yang lebih murah dibandingkan harga distributor membuat margin keuntungan tidak lagi bisa dimodifikasi sehingga membuat industri ini bisa dikategorikan kurang menarik untuk dimasuki oleh pemain baru. Kedua, banyaknya bengkel membuat daya tawar konsumen menjadi tinggi untuk berpindah dari satu bengkel ke bengkel lain. Ini merupakan salah satu faktor yang tidak menguntungan karena insentif yang harus diberikan oleh bengkel untuk menjaga konsumen menjadi sangat besar. Hal ini juga menjadi pendukung argumen bagi Trijaya Ban 83 untuk mengimplementasikan konsep one-stop service sebagai strategi menjaga konsumen dari berpindah ke rival lain.

Analisis eksternal kedua adalah analisis PESTEL. Berdasarkan analisis PESTEL, maka Trijaya Ban 83 dapat memanfaatkan kebijakan politik yang diambil pemerintah seperti kebijakan mobil Low Cost Green Car (LCGC) yang berperan positif dalam mendorong konsumsi mobil nasional meningkat. Jumlah mobil yang meningkat membuat potensi pasar 
yang lebih luas bagi Trijaya Ban 83. Adanya fenomena taksi online dan ekspektasi tinggi terhadap pelayanan juga harus diperhatikan oleh Trijaya Ban 83 karena kombinasi dari kedua faktor tersebut dan kebijakan LCGC bisa menjadi dasar pengambilan kebijakan strategis seperti bengkel one-stop service dan menentukan segmen pasar baru untuk diajak kerja sama, yaitu pemilik mobil-mobil online yang membutuhkan perawatan mobil yang lebih sering dan berkala.

Kebijakan politik juga memberi ancaman yang cukup berbahaya bagi Trijaya Ban 83 karena kedepannya pemerintah akan memfokuskan kepada transportasi umum yang dapat membuat penggunaan mobil pribadi berkurang. Hal ini memberikan tugas besar kepada bengkel Trijaya Ban 83 agar kedepannya bengkel tetap dapat mengambil keuntungan dikala situasi kompetisi eksternal yang cukup ketat

\section{Analisis SWOT}

Analisis SWOT merupakan analisa yang membahas internal dan eksternal perusahaan, analisa ini memberi gambaran mengenai kekuatan dan kelemahan perusahaan, peluang yang dapat digarap oleh perusahaan serta ancaman dari luar perusahaan yang dapat menganggu aktivitas bisnis (gamble et all, 2013). Analisis SWOT Trijaya Ban 83 digunakan untuk melihat keadaan internal dan eksternal Trijaya Ban 83 secara simultan. Hasil dari identifikasi SWOT yang dilakukan penulis kepada Trijaya Ban 83 bisa dilihat pada tabel 2 .

\begin{tabular}{l}
\hline Strength (Kekuatan) \\
\hline - Pelayanan yang baik serta cepat \\
- Harga yang kompetitif \\
- Kelengkapan produk dalam bengkel \\
- Penyelesaian masalah yang solutif \\
- Reputasi Trijaya Ban 83 yang sudah bagus \\
- Lokasi Bengkel yang strategis \\
- Manajemen sudah diisi oleh orang yang ahli \\
- Teknologi yang modern \\
- System pencatatan penjualan yang mumpuni
\end{tabular}

\section{Weakness (Kelemahan)}

- Kondisi lingkungan bengkel yang kurang bersih

- Penampilan karyawan yang kurang menarik

- Struktur biaya yang tidak jelas

- Kurangnya perhatian sector B2B

- Motivasi pekerja rendah

- Tidak memiliki sistem pencatatan database pelanggan

- Tidak strategi pemasaran

- Tidak melakukan riset mengenai keinginan konsumen

- Tidak ada standar pelayanan yang jelas

\section{Threat (Ancaman)}

- Tingginya penggunaan Trend aplikasi berbasis online kualitas transportasi public

- Tingginya tingkat kepemilikan mobil di Indonesia

- Adanya LCGC (Low Cost Green Car) yang disubsidi pemerintah

\section{Tabel 2. Analisis SWOT Trijaya Ban 83}

Berdasarkan analisis SWOT diatas maka didapatkan kesimpulan bahwa strategi yang bisa diterapkan oleh Trijaya Ban 83 dalam memanfaatkan kesempatan yang ada dengan memaksimalkan kekuatan yang dimiliki adalah dengan menyasar rental mobil yang menjadi mitra taksi online sebagai segmen pasar baru dan melakukan kerja sama dengan komunitas mobil LCGC. Strategi memanfaatkan kekuatan yang dimiliki Trijaya Ban 83 dalam menghadapi 
ancaman yang dihadapi adalah menciptakan marketing plan yang baik dan mulai memaksimalkan bisnis secondary, yaitu pelayanan perbaikan mobil, karena bisnis utama, yaitu penjualan ban mendapatkan ancaman serius dari e-commerce penjualan ban. Strategi yang dapat dieksekusi oleh Trijaya Ban dalam menutupi kelemahan dari peluang yang muncul di pasar adalah melakukan pengoptimalkan data pelanggan yang dimiliki oleh bengkel Trijaya Ban 83 dimana bengkel harus melakukan cross selling dan follow up kepada pelanggan lama agar mereka terus memakai jasa bengkel Trijaya Ban 83 dikala tingginya kompetisi bengkel.

\section{Analisis Kesenjangan}

Gap Analysis adalah analisa mengenai kondisi ideal yang diharapkan oleh perusahaan dan dibandingkan dengan kondisi yang saat ini sedang terjadi dengan identifikasi melalui analisa kondisi internal, eksternal dan analisa SWOT. Hal ini akan dijabarkan pada tabel 3 dibawah ini.

Tabel 3 Analisis Kesenjangan Trijaya Ban 83

\begin{tabular}{|c|c|c|c|c|}
\hline No & Indikator & Kondisi Ideal & Kondisi Aktual & Rencana \\
\hline 1 & $\begin{array}{l}\text { SWOT } \\
\text { (Weakness) }\end{array}$ & $\begin{array}{ll}\text { Memiliki } & \text { sitem } \\
\text { evaluasi kerja }\end{array}$ & $\begin{array}{l}\text { Tidak memiliki motivasi } \\
\text { kerja }\end{array}$ & $\begin{array}{l}\text { Menciptakan system } \\
\text { evaluasi kerja berbasis KPI } \\
\text { (Key Performance Indicator) }\end{array}$ \\
\hline 2 & $\begin{array}{l}\text { SWOT } \\
\text { (Weakness) }\end{array}$ & $\begin{array}{l}\text { Mekanik memiliki } \\
\text { motivasi kerja }\end{array}$ & $\begin{array}{l}\text { Mekanik tidak memiliki } \\
\text { motivasi kerja }\end{array}$ & $\begin{array}{l}\text { Menerapkan reward system } \\
\text { untuk mekanik yang } \\
\text { berprestasi }\end{array}$ \\
\hline 3 & $\begin{array}{l}\text { SWOT } \\
\text { (Weakness) }\end{array}$ & $\begin{array}{l}\text { Konsumen } \\
\text { mendapatkan } \\
\text { pelayanan lebih } \\
\text { karena merupakan } \\
\text { kontrIbusi pendapatan } \\
\text { terbesar }\end{array}$ & $\begin{array}{l}\text { Kondisi } \text { B2B tidak } \\
\text { mendapatkan pelayanan } \\
\text { lebih / sama dengan } \\
\text { retail }\end{array}$ & $\begin{array}{lr}\text { Menciptakan } & \text { strategi } \\
\text { Customer } & \text { Relationship } \\
\text { Management } & \text { untuk } \\
\text { mengelola konsumen besar. }\end{array}$ \\
\hline 4 & $\begin{array}{l}\text { SWOT } \\
\text { (Weakness) }\end{array}$ & $\begin{array}{lr}\text { Memiliki } & \text { database } \\
\text { konsumen } & \text { yang } \\
\text { lengkap } & \\
\end{array}$ & $\begin{array}{l}\text { Tidak memiliki database } \\
\text { konsumen yang lengkap }\end{array}$ & $\begin{array}{l}\text { Membuat database profile } \\
\text { konsumen yang lengkap }\end{array}$ \\
\hline 5 & $\begin{array}{l}\text { SWOT } \\
\text { (Weakness) }\end{array}$ & $\begin{array}{l}\text { Memilki struktur } \\
\text { biaya yang jelas } \\
\text { terhadap produk dan } \\
\text { jasa yang ditawarkan }\end{array}$ & $\begin{array}{l}\text { Tidak memiliki struktur } \\
\text { biaya yang jelas } \\
\text { terhadap produk dan } \\
\text { jasa yang ditawarkan }\end{array}$ & $\begin{array}{l}\text { Menghitung struktur biaya } \\
\text { produk dan jasa yang } \\
\text { ditawarkan oleh Trijaya Ban } \\
83\end{array}$ \\
\hline 6 & $\begin{array}{l}\text { Marketing Mix } \\
\text { (Process) }\end{array}$ & $\begin{array}{l}\text { Memiliki standar } \\
\text { kualitas pelayan }\end{array}$ & $\begin{array}{l}\text { Tidak memiliki standar } \\
\text { kualitas pelayanan }\end{array}$ & $\begin{array}{l}\text { Menciptakan SOP (Standard } \\
\text { Operating Procedure) agar } \\
\text { pelayanan dapat standar } \\
\text { antar mekanik }\end{array}$ \\
\hline 7 & $\begin{array}{l}\text { Marketing Mix } \\
\text { (Promotion) }\end{array}$ & $\begin{array}{ll}\text { Memiliki } & \text { strategi } \\
\text { promosi } & \text { melalui } \\
\text { media sosial } & \\
\end{array}$ & $\begin{array}{l}\text { Belum memiliki strategi } \\
\text { promosi melalui media } \\
\text { sosial }\end{array}$ & 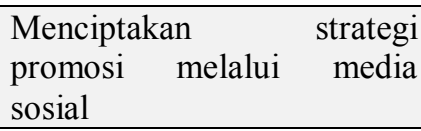 \\
\hline 8 & $\begin{array}{l}\text { Marketing Mix } \\
\text { (Promotion) }\end{array}$ & $\begin{array}{l}\text { Adanya } \text { alokasi dana } \\
\text { untuk melakukan } \\
\text { aktivitas pemasaran } \\
\end{array}$ & $\begin{array}{l}\text { Tidak ada alokasi dana } \\
\text { untuk melakukan } \\
\text { aktivitas pemasaran }\end{array}$ & $\begin{array}{l}\text { Membuat rencana pemasaran } \\
\text { untuk menghitung budgeting } \\
\text { dana. }\end{array}$ \\
\hline 9 & $\begin{array}{l}\text { Business } \\
\text { Canvas }\end{array}$ & $\begin{array}{l}\text { Memiliki strategi } \\
\text { untuk meningkatkan } \\
\text { customer retention }\end{array}$ & $\begin{array}{l}\text { Tidak memiliki strategi } \\
\text { untuk meningkatkan } \\
\text { customer retention }\end{array}$ & $\begin{array}{l}\text { Menciptakan } \\
\text { Customer } \\
\text { management } \\
\text { menigkatkan } \\
\text { retention. }\end{array}$ \\
\hline 10 & Listening Gap & $\begin{array}{l}\text { Perusahaan } \\
\text { mengetahui } \\
\text { ekspektasi pelanggan }\end{array}$ & $\begin{array}{lr}\text { Perusahaan } & \text { tidak } \\
\text { mengetahui } & \text { ekspektasi } \\
\text { pelanggan } & \\
\end{array}$ & $\begin{array}{l}\text { Melakukan survey terhadap } \\
\text { pelanggan dan memberikan } \\
\text { pelayan yang sesuai. }\end{array}$ \\
\hline
\end{tabular}


Berdasarkan tabel diatas maka hasil identifikasi kesepuluh permasalahan yang muncul dari kesenjangan diberi pemeringkatan untuk menentukan urutan kepentingan masalah bagi proses bisnis Trijaya Ban 83. Penentuan urutan kepentingan ini penting sebagai dasar dalam menganalisis permasalahan yang ada di Trijaya Ban 83 menggunakan analisis Pareto. Analisis Pareto berguna untuk menyelesaikan masalah yang paling penting dan memberikan dampak signifikan pada penyelesaian masalah secara keseluruhan. Analisis Pareto memiliki pendakatan bahwa $80 \%$ dampak berasal dari $20 \%$ masalah. Pendekatan Pareto dapat membuat penelitian fokus pada masalah-masalah yang berkontribusi $80 \%$ dari total masalah. Langkah yang digunakan untuk memberi nilai dan bobot pada masalah adalah melalui sesi diskusi dengan manajemen Trijaya Ban 83 tentang tingkat kepentingan dan dampak yang dihasilkan oleh masalah terhadap proses bisnis dari Trijaya Ban 83. Pemberian nilai diberikan pada angka 1 hingga 10 dengan rincian angka 1 berarti sulit untuk diterapkan dan angka 10 berarti mudah untuk diterapkan. Pemberian bobot dari angka 1 hingga 10 dengan rincian angka 1 berarti kondisi tidak bermasalah dan angka 10 berarti kondisi sangat bermasalah. Hasil dari diskusi pemberian nilai dan bobot pada masalah bisa dilihat pada tabel 3 berikut:

Tabel 4. Pembobotan Permasalahan UMKM

\begin{tabular}{lllllll}
\hline No & \multicolumn{1}{c}{ Masalah } & Nilai & Bobot & Kontribusi & $\begin{array}{c}\text { Persentase } \\
\text { DistrIbusi }\end{array}$ & $\begin{array}{c}\text { Persentasi } \\
\text { Akumulasi }\end{array}$ \\
\hline 1 & $\begin{array}{l}\text { Memiliki Struktur Biaya yang } \\
\text { jelas }\end{array}$ & 10 & 9 & 90 & $18.36 \%$ & $18.36 \%$ \\
\hline 2 & Ada standar kualitas pelayan & 8 & 8 & 64 & $13.06 \%$ & $31.42 \%$ \\
\hline 3 & $\begin{array}{l}\text { Memiliki database konsumen } \\
\text { yang lengkap }\end{array}$ & 8 & 8 & 64 & $13.06 \%$ & $44.48 \%$ \\
\hline 4 & $\begin{array}{l}\text { Mengetahui ekspektasi } \\
\text { pelanggan }\end{array}$ & 8 & 7 & 56 & $11.42 \%$ & $55.9 \%$ \\
\hline 5 & $\begin{array}{l}\text { Memiliki system evaluasi } \\
\text { kinerja }\end{array}$ & 8 & 7 & 56 & $11.42 \%$ & $67.32 \%$ \\
\hline 6 & Program Khusus B2B & 7 & 7 & 49 & $10 \%$ & $77.32 \%$ \\
\hline 7 & Melakukan strategi promosi & 6 & 6 & 36 & $7.34 \%$ & $84.66 \%$ \\
\hline 8 & $\begin{array}{l}\text { Pengalokasian dana untuk } \\
\text { pemasaran }\end{array}$ & 6 & 6 & 36 & $6.12 \%$ & $92 \%$ \\
\hline 9 & $\begin{array}{l}\text { Mekanik memiliki motivasi } \\
\text { kerja }\end{array}$ & 6 & 5 & 30 & $1.88 \%$ & $98.12 \%$ \\
\hline 10 & $\begin{array}{l}\text { Memiliki rencana pemasaran } \\
\text { yang jelas }\end{array}$ & 3 & 3 & 9 & $100 \%$ \\
\hline
\end{tabular}

Berdasarkan kodifikasi dari analisis kesenjangan dan diagram Pareto, maka strategi yang bisa dilakukan untuk mencapai kondisi ideal agar dapat bersaing dengan kompetitor di aspek pemasaran adalah memiliki strategi pemasaran berbasis data pelanggan dimana hal tersebut dapat menyelesaikan permasalahan database konsumen dan meningkatkan standar pelayanan bengkel. Strategi pemasaran yang akan digunakan penulis untuk mengatasi kesenjangan di aspek pemasaran ini adalah menggunakan strategi Customer Relationship
Management untuk meningkatkan penjualan bengkel Trijaya Ban 83

\section{METODE PELAKSANAAN}

Metode yang digunakan untuk menggali data dan informasi UMKM dalam penelitian business coaching ini adalah metode penelitian eksploratori. Menurut Malhotra (2009), metode ini berfungsi untuk mencari, mengidentifikasi, dan memahami masalah secara menyeluruh. Pengumpulan data dilakukan dengan dua cara, yaitu wawancara dan observasi. Objek yang diwawancara dan diobservasi pada penelitian ini 
terdiri dari pihak manajemen, pihak karyawan yang diwakili oleh divisi sales, divisi bongkar pasang, divisi engine dan juru parkir.

Teknik analisis data yang digunakan dalam melaksanakan business coaching ini menggunakan pendekatan analisis kualitatif. Ada tiga Aktivitas dalam menganalisis data pada pendekatan kualitatif, yaitu reduksi data, penyajian data, dan verifikasi serta penarikan kesimpulan.

\section{HASIL DAN PEMBAHASAN}

Permasalahan di bidang pemasaran yang teridentifikasi selama proses coaching yang dilakukan selama 6 sesi pertemuan dengan menggunakan analisis kesenjangan di Trijaya Ban 83 adalah belum adanya database pelanggan yang lengkap di Trijaya Ban 83. Manajemen Trijaya Ban 83 memiliki rencana strategis untuk menjadi bengkel yang memberikan pelayanan jasa perbaikan dan perawatan mobil yang lengkap dan berkualitas. Rencana ini mulai muncul setelah manajemen Trijaya Ban 83 melihat tren masa depan yang akan dihadapi oleh Trijaya Ban 83 dengan kehadiran tyrepac.co.id yang menawarkan harga ban yang tidak dapat disaingi oleh distributor ataupun bengkel manapun dan juga visi pemerintah untuk meningkatkan transportasi umum. Oleh karena itu, muncul kesadaran dari manajemen Trijaya Ban 83 bahwa mereka harus berbenah dan memiliki langkah-langkah strategis dari sekarang untuk memenangi kompetisi bisnis di masa depan. Kinerja bengkel Trijaya Ban 83 untuk melaksanakan rencana strategis tersebut perlu dievalusi secara berkala untuk melihat sejauh mana kinerja bengkel telah merealisasikan rencana bisnis yang telah dirumuskan.

Bengkel Trijaya Ban 83 telah memiliki banyak pelanggan setiap harinya, dimana sekitar 1500 pelanggan dalam kurun waktu satu bulan. Pelanggan yang datang dan pergi setelah mendapatkan pelayanan dari Trijaya Ban 83 merupakan data yang berharga bagi Trijaya Ban 83 dimana bengkel dapat memperoleh data berupa : produk atau jasa yang paling sering dibeli, data pelanggan yang sering datang, dan data pelanggan yang melakukan transaksi bisnis diatas rata-rata pelanggan. Hal ini dapat digunakan oleh Bengkel Trijaya Ban 83 untuk melakukan fungsi Customer Relationship Management terhadap pelanggan spesial tersebut.

Berdasarkan data Importance Performance Analysis (Dimas Ahimsa, 2016) Bengkel Trijaya Ban 83 dalam layanan jasa, dapat dibagi kedalam empat kuadran penting yaitu kuadran A (Tingkatkan Kinerja), Kuadran B (Pertahankan Kinerja), Kuadran C (Prioritas Rendah), Kuadran D (Kinerja Berlebihan). Pada permasalahan ini, untuk membahas masalah dari Trijaya Ban 83 dapat dilihat dari Kuadran A (Tingkatkan Kinerja) yaitu:

1. Pemahaman karyawan bengkel terhadap kebutuhan spesifik konsumen

2. Daya Tarik fasilitas fisik

3. Daya Tarik penampilan karyawan

Ketiga hal datas merupakan hal-hal yang harus ditingkatkan oleh bengkel Trijaya Ban 83 karena dianggap masih belum cukup memenuhi kriteria. Menurut coachee daya tarik fasilitas fisik dan daya tarik penampilan karyawan merupakan suatu hal yang sudah ada standarisasi dari Bridgestone sehingga tidak dapat dirubah tanpa seizin dengan Bridgestone. Hal yang saat ini dirasa sangat penting oleh pihak bengkel Trijaya Ban 83 adalah mengenai pemahaman karyawan bengkel terhadap kebutuhan spesifik konsumen.

Untuk menyelesaikan permasalahan ini, strategi yang diusulkan adalah dengan penerapan strategi Customer Relationship Management pada bengkel Trijaya Ban 83 dimana akan dibagi kedalam empat tahap, yaitu

a. Tahap1 : Pengelompokan data Pelanggan Trijaya Ban 83

Pada tahap pertama, coach akan menganalisa data pelanggan yang selama ini sudah berjalan dalam bengkel Trijaya Ban 83 dan melakukan review untuk poin- poin yang harus ditambah agar bengkel Trijaya Ban 83 memiliki data yang lengkap dan dapat 
digunakan untuk melakukan Customer Relationship Management.

Pada saat ini, Bengkel Trijaya Ban 83 menggunakan program akuntansi bernama MYOB untuk mencatat penjualan dimana data tersebut tergabung untuk pelaporan keuangan dan sumber database pelanggan. Untuk informasi yang tercantum dalam database tersebut saat ini adalah tanggal transaksi,nomor plat mobil, nama (pemilik / supir dari pemilik mobil), Contact Person, alamat E-Mail, barang/ jasa yang dijual, mekanik yang melayani dan informasi lainlain

Untuk pencatatan data saat ini sudah cukup merepresentasikan data pelanggan yang dibutuhkan untuk Customer Relationship Management, namun terdapat beberapa hal yang perlu diperbaiki, yaitu:

1) Nama, untuk kolom yang diinput pada nama adalah nama dari pemilik mobil / Key person yang bertanggung jawab atau Perusahaan yang memiliki mobil tersebut dalam transaksi produk atau service mobil tersebut. Hal ini bertujuan untuk mengetahui lebih detail nama pelanggan yang akan dilayani

2) Nomor plat mobil, untuk kolom nomor plat mobil, lebih baik diganti atau ditambahkan jenis mobil yang diperbaiki. Hal ini bertujuan untuk mengetahui frekuensi tipe mobil yang diperbaiki sehingga manajemen dapat mengambil langkah strategis.

3) Testimoni , untuk penambahan kolom testimonis bertujuan agar setiap pelanggan dapat memberikan informasi/ keluhan/ prospek bisnis kedepannya sehingga Bengkel Trijaya Ban 83 dapat memberikan follow up atas produk tersebut

Setelah melakukan analisa data pelanggan bengkel Trijaya Ban 83 melalui laporan penjualan periode tahun 2016, diperoleh data ribuan transaksi setiap bulannya dimana rata-rata terjadi $+/-2000$ transaksi pada bengkel Trijaya Ban 83, dimana terdapat transaksi dengan nominal besar hingga puluhan juta untuk penjualan ban dalam jumlah besar dan transaksi nominal kecil hingga puluhan ribu untuk jasa seperti pengisian gas nitrogen.

Setelah membenahi seluruh data pelanggan yang muncul di Bengkel Trijaya Ban 83, hal berikutnya adalah mengelompokkan data pelanggan Trijaya Ban 83. Untuk selanjutnya, kelompok pelanggan ini akan disebut kelompok Fokus. Kelompok fokus adalah kelompok yang memberikan kontribusi pendapatan yang tinggi bagi bengkel Trijaya Ban 83 dan memiliki dampak yang signifikan untuk bengkel Trijaya Ban 83. Pengelompokan kelompok fokus antara lain :

1) Pelanggan yang telah transaksi di Trijaya Ban 83 lebih dari 3 tahun terakhir

2) Pelanggan yang memberikan kontribusi pendapatan lebih dari Rp 3.000.000,setiap bulan

3) Pelanggan yang memiliki hubungan $\mathrm{B} 2 \mathrm{~B}$ antara perusahaan

4) Pelanggan yang melakukan transaksi di Bengkel Trijaya Ban, 3 bulan sekali

5) Pelanggan yang memiliki mobil tipe luxury

Setelah melakukan analisa data penjualan bengkel Trijaya Ban 83 pada periode tahun 2016, dilakukan analisa pelanggan dengan mensortir pelanggan yang melakukan transaksi lebih dari Rp.3.000.000,dan mendapatkan hasil bahwa setiap bulan terdapat rata-rata 68 pelanggan yang berbedabeda. Melalui kesepakatan dengan coachee untuk data kelompok fokus kali ini, coachee kemudiann melakukan pemfokusan CRM dengan 50 pelanggan yang memberikan laba terbesar kepada bengkel Trijaya Ban 83 sehingga dilakukan pemilihan berdasarkan frekuensi (n) transaksi pelanggan tersebut melakukan transaksi di Bengkel Trijaya Ban 83 sehingga didapat data pelanggan sebagai berikut: 
Tabel 5. Top 50 Customer Bengkel Trijaya Ban 83

\begin{tabular}{llll}
\hline Nama Pelanggan & $\mathbf{n}$ & Nama Pelanggan & $\mathbf{n}$ \\
\hline CV. Palapa Jaya & 12 & Bp. Eko & 6 \\
\hline Madu Sari & 12 & CV. Kurnia Transindo & 6 \\
\hline PT. RAFA TRANSINDO & 12 & PT. FAST FOOD INDONESIA Tbk. & 6 \\
\hline REMAJA GUDANG AIR & 12 & Salim Ban & 6 \\
\hline Family Raya & 11 & ADIGUNA & 5 \\
\hline PT. ORIX INDONESIA FINANCE & 11 & Atek Parung & 5 \\
\hline SEMARANG BAN & 11 & Master Ban & 5 \\
\hline SUMBER MAKMUR CIKARANG & 11 & BRI Life & 5 \\
\hline Bianglala & 10 & PT. MARGA MAJU MAPAN & 5 \\
\hline Bp. David Cawang & 10 & PT. NET MEDIATAMA TELEVISI & 5 \\
\hline Palem Vulkanisir & 10 & PT. PRIMA SENTOSA ABADI & 5 \\
\hline REMAJA ADIJAYA & 10 & PT. ADES TOUR & 5 \\
\hline SUMBER UTAMA & 10 & Amin Motor & 4 \\
\hline PO. NUSANTARA & 10 & Aneka Guna Bogor & 4 \\
\hline PT. MAJU MAKMUR SEMPURNA & 10 & Eka Jaya Cilegon & 4 \\
\hline RAJAWALI CIANJUR & 9 & Karya Mandiri transport & 4 \\
\hline JOKO JAYA BAN & 9 & PT. ELANG BUANA PERKASA & 4 \\
\hline UD. LAKSANA MANDIRI & 9 & PT. KEMFOODS & 4 \\
\hline New Sahabat & 8 & PT. KARYA KREASI PUTRA SATYA & 4 \\
\hline PT. SRI LOKA & 8 & PT. SARI JASA TRANS UTAMA & 4 \\
\hline PT. ANUGERAH ABADI CAHAYA & 8 & PT. WINDA MULTITRA ABADI & 4 \\
\hline SEJATI & 8 & BP. HASUGIAN & 4 \\
\hline PT. RONA MITRA ABADI & 7 & JAYA TRAIDER BAN & 4 \\
\hline AGOES BAN NAGREG & 6 & Metropolitan & 4 \\
\hline ANGKUTAN RATU TIARA & 6 & PT. FRISIAN FLAG INDONESIA & \\
\hline Anugerah Ban Otista & & & 4 \\
\hline
\end{tabular}

Setelah mendapatkan jumlah kelompok fokus, Bengkel Trijaya Ban 83 dapat melangkah ke proses berikutnya untuk melakukan strategi Customer Relationship Management.

b. Tahap 2: Strategi Customer Relationship Management

\section{Strategi Customer Relationship} Management bertujuan untuk mempertahankan pelanggan yang sudah ada agar terus bertransaksi di bengkel Trijaya Ban 83. Untuk mencapai hal tersebut terdapat beberapa strategi yang dapat dilakukan, antara lain:

1) Sapa Nama Kelompok Fokus Kelompok fokus adalah kumpulan pelanggan Trijaya Ban 83 yang berdampak besar dalam kelangsungan usaha bengkel, sehingga perlu ada diferensiasi perlakuan dalam pelayanan kelompok fokus. Dalam hal ini, mekanik diharuskan untuk menghapal nama dan kebiasaan transaksi kelompok fokus sehingga pada saat pelanggan muncul, mekanik dapat melayani dengan cepat dan menjalin relasi dengan baik.

2) Discount untuk kelompok fokus

Seluruh produk bengkel Trijaya Ban 83 merupakan produk yang dapat diperoleh di bengkel lain sehingga untuk memberikan diferensiasi untuk kelompok fokus, akan diberikan diskon khusus terhadap produk atau jasa yang 
ditawarkan sehingga kelompok foku tetap melakukan service di bengkel Trijaya Ban 83

3) Gathering Kelompok Fokus

Dalam industri perbengkelan, terdapat banyak produk / layanan jasa yang dapat ditawarkan serta berbagai informasi penting mengenai otomotif. Hal ini penting agar kelompok fokus menjadi kelompok yang paling pertama mengetahui informasi tersebut karena persentasi kemungkinan produk / jasa akan terjual akan lebih besar.

4) Reminder Layanan Service Berkala

Service mobil adalah layanan yang seharusnya dilakukan secara berkala, bukan sesuatu yang dilakukan pada saat mobil mengalami kerusakan. Dalam hal ini, pelayanan seperti ganti oli harus dilakukan 3 bulan sekali, Spooring, Balancing dan Tune up dilakukan 6 bulan sekali, dan penggantian ban 3 tahun sekali. Hal ini bertujuan untuk melindungi keamanan pelanggan dalam berkendaraan. Dalam menangani seluruh pelanggan Trijaya Ban 83, bengkel akan memfokuskan reminder melalui telepon kepada kelompok fokus terlebih dahulu.

5) Parsel pada hari raya

Bengkel Trijaya Ban 83 selama ini memiliki program pengiriman parcel kepada pelanggan yang telah lama bertransaksi kepada bengkel Trijaya Ban 83 , namun untuk pelanggan yang selama ini menerima parcel merupakan pelanggan yang memiliki hubungan pertemanan dengan pemilik bengkel dan bukan merupakan pelanggan yang memberikan dampak keuntungan bagi bengkel Trijaya Ban 83. Dengan adanya kelompok fokus ini, maka bengkel Trijaya Ban 83 dapat memberikan apresiasi lebih kepada pelanggan yang memberikan dampak besar bagi bengkel Trijaya Ban 83.

c. Tahap 3: Implementasi Customer Relationship Management
Untuk implementasi, hal ini akan dilakukan terhadap tim sales secara berkala serta melakukan penyampaian informasi kepada pemilik mengenai hasil yang diperoleh dari penerapan Customer Relationship Management. Hasil CRM yang berhasil dilaksanakan akan dicatat menjadi poin penting, dan jika belum berhasil maka akan dicatat sebagai perbaikan di pengelompokan data.

d. Tahap 4: Evaluasi

Tahap evaluasi menganalisa proses CRM dari awal hingga akhir, mengetahui apakah pengelompokan data yang dilakukan sudah sesuai atau memerlukan perbaikan, dan analisa produk atau service yang paling diminati. Untuk pengelompokan data nasabah, jika dirasa masih kurang, dapat ditambah dengan cara memperbesar range kriteria pelanggan fokus bengkel Trijaya Ban 83.

\section{SIMPULAN}

Berdasarkan proses business coaching secara keseluruhan dengan pihak manajemen bengkel Trijaya Ban 83 , serta melakukan analisa data penjualan tahun 2016, dapat disimpulkan bahwa Trijaya Ban 83 sudah memiliki pelanggan tetap yang sangat banyak yang melakukan transaksi rutin secara bulanan. Hal ini bisa terlihat dari banyaknya jumlah pelanggan kelompok Fokus bengkel Trijaya Ban 83 dan secara konsistensi frekuensi transaksi dilakukan secara rutin dimana dalam satu tahun dapat dilakukan 4-5 kali dan terdapat beberapa pelanggan yang melakukan transaksi bulanan dalam jumlah besar. Berdasarkan analisa, terdapat 68 pelanggan setiap bulannya yang merupakan kriteria kelompok Fokus Trijaya Ban 83 dimana bengkel Trijaya Ban 83 wajib melakukan pelayanan lebih untuk dapat menggarap potensi bisnis yang ada pada pelanggan dari kelompok Fokus.

\section{SARAN}

Dengan adanya implementasi Customer Relationship Management, diharapkan pelanggan akan semakin loyal kepada bengkel Trijaya Ban 83 dan terus memilih bengkel Trijaya Ban 83 
sebagai bengkel utama dan mereferensikan bengkel Trijaya Ban 83 kepada pelanggan lain. Dalam tahap awal, bengkel Trijaya Ban 83 akan memfokuskan kepada 50 pelanggan yang memberikan kontribusi pendapatan tertinggi dimana kedepannya akan bertambah dengan peningkatan sistem teknologi dan sumber daya yang memadai. Untuk Bengkel Trijaya Ban 83, Customer Relationship Management juga membantu pihak manajemen untuk menganalisa data sehingga dapat memberikan service yang lebih baik dibandingkan bengkel lain.

\section{DAFTAR PUSTAKA}

Baran,Galka \& Strunk (2008). Principles of Customer Relationship Management. USA:Thomson Higher Education.

Barney, J. B. (1995). Looking Inside for Competitive Advantage. Academy of Management Executive, Vol. 9, Issue 4, pp. $49-61$

BI.go.id. $B I$ Rate. Retrived from: http://www.bi.go.id/en/moneter/birate/data /Default.aspx diakses pada tanggal $15 \mathrm{Mei}$ 2017 Pukul 20.00 WIB

BI.go.id. Kurs Transaksi Bank Indonesia. Retrived from: http://www.bi.go.id/id/moneter/informasikurs/transaksi-bi/Default.aspx diakses pada tanggal 15 Mei 2017 Pukul 20.00 WIB

Bps.go.id. Pertumbuhan Ekonomi Indonesia Triwulan 12015 tumbuh 4.71 Persen. Retrived from: https://www.bps.go.id/Brs/view/id/1143 pada tanggal 12 Juni 2016, pukul 15.45 WIB

Economist.com. customer relationship management. Retrieved from: http://www.economist.com/node/1429888 $\underline{6}$ diakses pada tanggal 15 Mei 2017 Pukul 20.00 WIB

Gajiumr.com. Gaji UMR Jakarta tahun 2017. Retrieved from https://www.gajiumr.com/umr-jakarta/ diakses pada tanggal 15 Mei 2017 Pukul $20.00 \mathrm{WIB}$
Gamble, P. T. (2013). Essentials of Strategic Management: The Quest for Competitive Advantege. New York: McGraw-Hill Education.

Gamble, John E., Peteraf, Margareth A., Thompson, Arthur A.,Essentials of Strategic Management The Quest for Compettive Advantage - Fourth Edition. 2015. McGraw-Hill.

Hukumonline.com. Maksimal kontrak kerja. Retrieved from: http://www.hukumonline.com/klinik/detail /c11429/maksimal-kontrak-kerja diakses pada tanggal 15 Mei 2017 Pukul 20.00 WIB

Indonesia-investments.com. Low cost green car to boost indonesia's 2016 car sales. Retrieved from: http://www.indonesiainvestments.com/id/news/todays-

headlines/low-cost-green-car-to-boostindonesia-s-2016-car-sales/item7092

diakses pada tanggal 15 Mei 2017 Pukul $20.00 \mathrm{WIB}$

Indonesia-investments.com. Produk domestik bruto Indonesia. Retrieved from: http://www.indonesiainvestments.com/id/keuangan/angkaekonomi-makro/produk-domestik-brutoindonesia/item253? diakses pada tanggal 15 Mei 2017 Pukul 20.00 WIB

Industri Otomotif Menjadi Indikator Pertumbuhan http://www.beritasatu.com/mobil/379281wapres-industri-otomotif-jadiindikator pertumbuhan.html. diakses pada tanggal 15 Mei 2017 Pukul 20.00 WIB

Kemenkeu.go.id. wawancara eksklusif mentri keuangan tentang tax amnesty Retrieved from:http://www.kemenkeu.go.id/taxamne sty diakses pada tanggal 15 Mei 2017 Pukul 20.00 WIB

Kemenperin.go.id Peran Penting Industri otomotif. Retrieved from: http://www.kemenperin.go.id/artikel/1662 1/Peran-Penting-Industri-Otomotif diakses pada tanggal 15 Mei 2017 Pukul 20.00 WIB 
Kotler, P., "Managing Customer Relationships: Lessons from the Leaders", The Economist Intelligence Unit, 1998

Kotler, P., \& Keller, K. L. Marketing Management 14th Edition. 2012. New Jersey: Pearson.

Mehrdad alipour and Mohammad Hallaj. 2011. The effect of Customer Relationship Management (CRM) on Achieving Competitive advantage of Manufacturing Tractor. USA: Globar Journal of Management and Businesss research vol.11 issue 5 Version 1.0

Mullins, J. W., \& Walker, O. C. (2013). Marketing Management :a strategic decisionmaking approach 8th edition. New York: McGraw-Hill

Osterwalder, A., \& Pigneur, Y. (2014). Business Model Generation. Jakarta: Elex Media Kompetindo.

Pasar Otomotif Berpeluang Tumbuh http://www.gaikindo.or.id/jumlahkelasmenengah-naik-pasar-otomotif- berpeluang-tumbuh/. diakses pada tanggal 15 Mei 2017 Pukul 20.00 WIB

Peningkatan Masyarakat Kelas Menengah di Indonesia.

http://www.nielsen.com/id/en/insights/new s/2014/meet-the-newindonesian-

consumer-class-of-2020.html. diakses pada tanggal 15 Mei 2017 Pukul 20.00 WIB

Profil bisnis Usaha mikro, kecil, dan menengah. http://www.bi.go.id/id/umkm/penelitian/na sional/kajian/Documents/Profil\%20Bisnis \%20UMKM.pdf. Diakses pada tanggal 15 Mei 2017 Pukul 20.00 WIB

Sindonews.com.Pertumbuhan ekonomi Indonesia termasuk tertinggi di dunia. Retrieved from: https://ekbis.sindonews.com/read/1156211 33/sri-mulyani-pertumbuhan-ekonomiindonesia-termasuk-tertinggi-di-dunia1479389615 diakses pada tanggal 15 Mei 2017 Pukul 20.00 WIB 